\title{
Carbon Dioxide Emission Analysis of Chilled Water Production by Using Gas Turbine Exhaust Heat
}

\author{
Adzuieen Nordin and Mohd Amin Abd Majid
}

\begin{abstract}
Carbon dioxide from exhaust heat emission is one of the major contributorsto the environmental pollutant in power generation plants. This problem could be addressed if the emitted exhaust heat is recovered. In cogeneration plant, the exhaust heat from the gas turbine is used to generate steam usingHeat Recovery Steam Generator. The steam from Heat Recovery Steam Generator is then used for chilled water generation in Steam Absorption Chillers by absorption process. This study analyzed the total estimated amount of $\mathrm{CO}_{2}$ released to the environment due to chilled water production by using gas turbine exhaust heat. University Teknologi PetronasMalaysia cogeneration system is used as a case study. The energy balance principlewas adopted for the analysis. Results indicate that approximately $44 \%$ of $\mathrm{CO}_{2}$ is avoided from being released to the environment by this process.
\end{abstract}

Index Terms-Absorption process, carbon dioxide emission, cogeneration and exhaust heat.

\section{INTRODUCTION}

It is a common practice to usechilled water as a cooling medium for district cooling systems. Chilled water is generated by absorption process in cogeneration systems. Cogeneration systems can be defined as the simultaneous production of electrical or thermal energy from a single energy source, by capturing exhaust heat from the gas turbines which would otherwise be rejected to the environment [1]. Cogeneration system has been installed to enhance the efficiency of generated power compared to the conventional plant. The enhancement is achieved through the utilization of exhaust heat from the gas turbine to generate additional energy.

The cogeneration systemconsists of Gas Turbine (GT), Heat Recovery Steam Generator (HRSG) and Steam Absorption Chiller (SAC). GT generates electricity for the power supply. During the generation of power by GT, exhaust gas is released to the environment. The exhaust heat is captured and diverted to HRSG for steam production. The steam in turn is channeled to SAC for the generation of chilled water. In the process of steam and chilled water generation heat is generated which is represented as heat loss in Fig. 1. However, the amount of heat loss recovered from the GT for chilled water generation by absorption process assists in enhancing efficiency of the cogeneration system as well as reduced the emission of exhaust heat to the environment thus reducing $\mathrm{CO}_{2}$ emission.

Carbon dioxide $\left(\mathrm{CO}_{2}\right)$ emission is one of the major sources contributed to the environmental pollutant. $\mathrm{CO}_{2}$ emission

Manuscript received July 10, 2013; revised August 17, 2013

Adzuieen Nordin and M Amin A Majid are with the Mechanical Engineering Department, Universiti Teknologi Petronas, Perak, Malaysia (e-mail:adzuieennordin@gmail.com,mamin_amajid@petronas.com.my). released to the environment by combustion of fossil fuels in transportation, manufacturing industries and the power generation system. In many power generation systems, the source of $\mathrm{CO}_{2}$ emission is the combustion process of the fuel. $\mathrm{CO}_{2}$ released to the environment by the combustion process gives rise to several environmental concerns which can threaten the sustainability of our ecosystem. Thus, a study on the $\mathrm{CO}_{2}$ emissions could assist in mitigation of this problem.

Carbon dioxide $\left(\mathrm{CO}_{2}\right)$ emission is one of the major sources contributed to the environmental pollutant. $\mathrm{CO}_{2}$ emission released to the environment by combustion of fossil fuels in transportation, manufacturing industries and the power generation system. In many power generation systems, the source of $\mathrm{CO}_{2}$ emission is the combustion process of the fuel. $\mathrm{CO}_{2}$ released to the environment by the combustion process gives rise to several environmental concerns which can threaten the sustainability of our ecosystem. Thus, a study on the $\mathrm{CO}_{2}$ emissions could assist in mitigation of this problem.

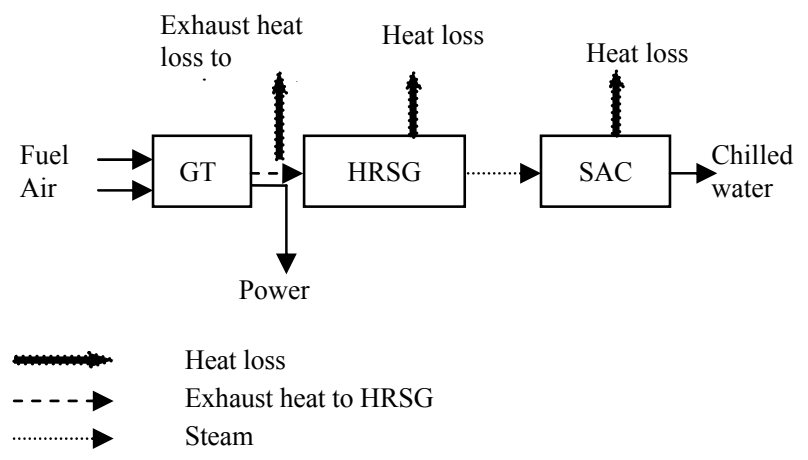

Fig. 1. Schematic diagram for cogeneration system.

\section{Methodology}

In order to assess the $\mathrm{CO}_{2}$ emissions, an energy balance model was developed based on the principle of First Law Thermodynamics. Using the energy balance model, the heat loss for GT, HRSG and SAC were evaluated. Based on the heat loss, the $\mathrm{CO}_{2}$ emission is then estimated from GT and HRSG.

\section{A. Energy Balance Model}

Fig. 2 shows a typical model for the GT.The GT consists of a compressor, combustor and turbine section. Ambient air is first compressed in the compressor. Fuel is added and combusted in the combustor. Most GT applications rely on natural gas or fuel oil for fuel. The combustion products exit the combustor and expand in the turbine section. The expansion drives an electric generator to generate electricity. The exhaust heat from the turbine is normally used to produce process steam or hot water. The steam in turn could 
either be used to power steam turbine or to produce chilled water for absorption process.

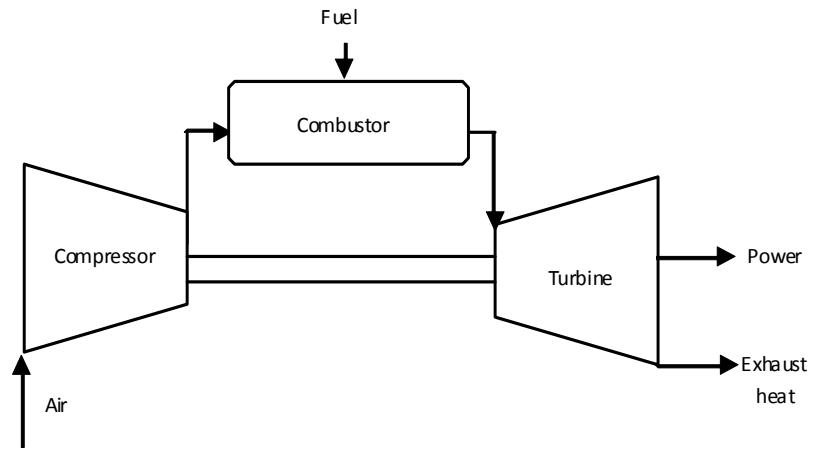

Fig. 2. Typical GT system.

Fig. 3 shows the energy balance model for the GT. For the analysis of the GT, the following assumptions were used;

- The gas turbine engine was at steady state.

- The process at the gas turbine was an adiabatic process.

- Heat loss due to lubrication was eliminated.

- Only $66.6 \%$ of the exhaust heat from the GT was taken into account of the steam conversion. The remaining is $33.4 \%$ of the exhaust heat was released to the environment [9].

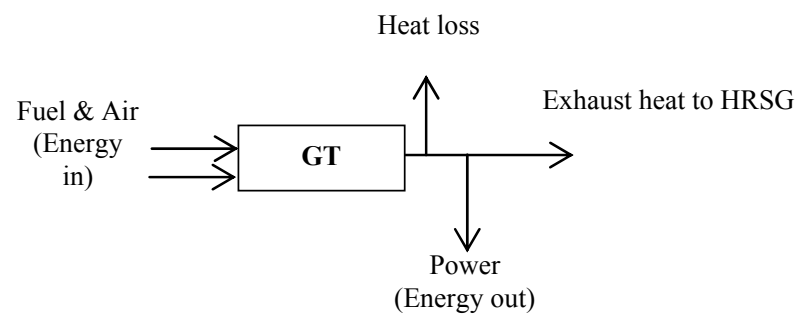

Fig. 3. Energy balance model for GT.

The heat loss is the exhaust heat released to the environment. The amount of exhaust heat used steam conversionwas the energy input for HRSG. The energy balance model for HRSG and SAC areshown in Fig. 4 and Fig. 5 respectively.

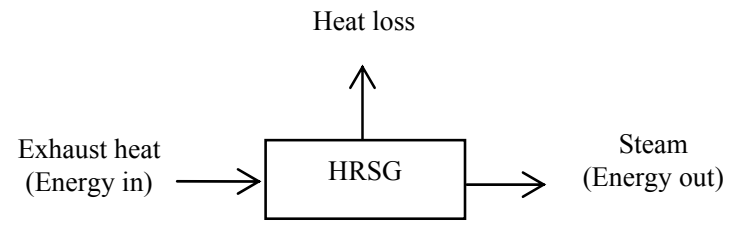

Fig. 4. Energy balance model for HRSG

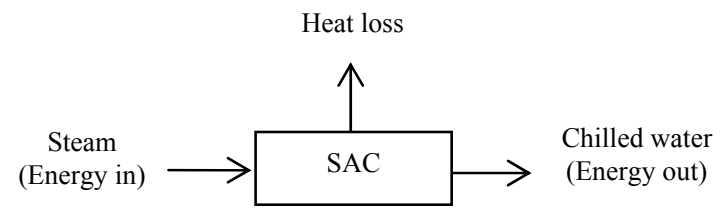

Fig. 5. Energy balance model for SAC.

\section{B. Heat Loss}

The energy balance equation was used to evaluate the energy input, energy output and the difference between them by using Eq. (1) [10].

$$
m_{i}\left(h_{i}+\frac{V_{i}^{2}}{2}+Z_{i}\right)+\dot{Q}=\dot{m}_{o}\left(h_{o}+\frac{V_{o}^{2}}{2}+Z_{o}\right)+\dot{W}
$$

where $\dot{\mathrm{m}}_{\mathrm{i}}, \dot{\mathrm{m}}_{\mathrm{o}}$ is mass flow rate $(\mathrm{kg} / \mathrm{s}), \mathrm{h}$ is enthalpy $(\mathrm{kg} / \mathrm{kJ})$, $\mathrm{V}$ is velocity $(\mathrm{m} / \mathrm{s}), \mathrm{Z}$ is elevation $(\mathrm{m}), \dot{\mathrm{Q}}$ is the rate of heat and $\dot{W}$ is power generated by the system. Mass and energy balance for any control volume with negligible potential and kinetic energy is expressed by Eq. (2);

$$
\dot{m}_{i}\left(h_{i}\right)+\dot{Q}=\dot{m}_{o}\left(h_{o}\right)+\dot{W}
$$

1) For the case of GT:

The exhaust heat released by the turbine was calculated as [11].

$$
\text { Energy loss }(G T)=\dot{m}_{g 3} C p_{g e x} T_{e x}
$$

where $\dot{m}_{g 3}$ is mass flow rate $(\mathrm{kg} / \mathrm{s}), T_{e x}$ is exhaust heat temperature $(\mathrm{K})$ and $C p_{\text {gex }}$ is specific heat of gas for the exhaust temperature (kJ/kg.K)

\section{2) For the case of HRSG:}

The HRSG generated steam by utilizing the energy in the exhaust heat from the gas turbine. Three assumptions were used to analyze the model namely [12]:

a) The temperature of steam coming out from $H R S G$ was kept constant at $177^{\circ} \mathrm{C}$.

b) The flow rate of steam from HRSG was 5.5T/h.

c) The total steam generated by HRSG was taken as energy input to $S A C$.

The heat loss for HRSG was calculated as:

$$
\begin{array}{r}
\text { Energy }_{\text {loss }}(\text { Heat loss }) \\
=\text { Energy }_{\text {in }}(\text { from exhaust heat }) \\
- \text { Energy }_{\text {out }}(\text { from steam })
\end{array}
$$

The calculation of energy in HRSG was expressed by :

$$
\text { Energy in }(H R S G)=\dot{m}_{e x} C p_{e x} T_{e x}
$$

where $\dot{m}_{e x}$ is mass flow rate of exhaust heat $(\mathrm{kg} / \mathrm{s}), C p_{e x}$ is specific heat of gas for the exhaust temperature (kJ/kg.K) and $T_{\text {ex }}$ is exhaust heat temperature $(\mathrm{K})$. For the amount of energy out was calculated as:

$$
\text { Energy out }(H R S G)=\dot{m}_{s t} C p_{s t} T_{s t}
$$

where $\dot{m}_{s t}$ is mass flow rate of steam $(\mathrm{kg} / \mathrm{s}), C p_{s t}$ is specific heat of steam temperature $(\mathrm{kJ} / \mathrm{kg} . \mathrm{K})$ and $T_{s t}$ is steam temperature $(\mathrm{K})$.

3) For the case of $S A C$ :

In $\mathrm{SAC}$, the steam from HRSG wasconverted to chilled water by absorption process. The heat loss due to this process was calculated as:

$$
\begin{array}{r}
\text { Energy } \left.y_{\text {loss }} \text { (Heat loss }\right) \\
=\text { Energy }_{\text {in }}(\text { from steam }) \\
- \text { Energy }_{\text {out }}(\text { from chilled water })
\end{array}
$$


The amount of energy in SAC is the amount of energy out of the HRSG. Whereas the amount of energy out from SAC was calculated as:

$$
\text { Energy }_{\text {out }} \text { of } S A C\left(Q_{\text {outSAC }}\right)=\dot{m}_{c h w} C p_{c h w} \Delta T_{c h w}
$$

where $\dot{m}_{c h w}$ is mass flow rate of chilled water $(\mathrm{kg} / \mathrm{s}), C p_{c h w}$ is specific heat of chilled water temperature $(\mathrm{kJ} / \mathrm{kg} . \mathrm{K})$ and $\Delta T_{c h w}$ isthe difference of chilled water temperature $(\mathrm{K})$ out and in of SAC.

\section{C. $\mathrm{CO}_{2}$ Emissions Evaluation}

The equivalent of $\mathrm{CO}_{2}$ being released to the environment was calculated based on $\mathrm{kWh}$ heat lossfor each of the GT and HRSG respectively. The equivalent of $\mathrm{CO}_{2}$ was based on 474 $\mathrm{g} / \mathrm{kWh}$ as reported by R. Kannan et al. [13].

Since the heat loss by SAC is through cooling system, it is assumed the heat loss from $\mathrm{SAC}$ does not contribute to $\mathrm{CO}_{2}$ emission.

The total of the amount of $\mathrm{CO}_{2}$ for chilled water production by GT exhaust heatwas estimated. Eq. (9) was used for analysis:

$$
\sum \mathrm{CO}_{2(\mathrm{cogen})}=\mathrm{CO}_{2(G T)}+\mathrm{CO}_{2(\mathrm{HRSG})}
$$

\section{CASE STUDY}

The absorption system of Universiti Teknologi Petronas (UTP) District Cooling plant as shown in Fig. 6 is taken as a case study. The plant started operation in April 2003. The plant operates on a 24 hour basis. During peak periods, the absorption system is operated with full load capacity. The exhaust heat from GT is used to generate steam by HRSG. A study on the conversion process have been done and the findings from the study indicate, only a maximum of $66.6 \%$ of the exhaust heat could be used to generate steam and the remaining was released to the environment [9]. The steam was used to generate chilled water by SAC. This study is to focus on the evaluation of $\mathrm{CO}_{2}$ emission during the process of chilled water production by using exhaust heat from the GT.

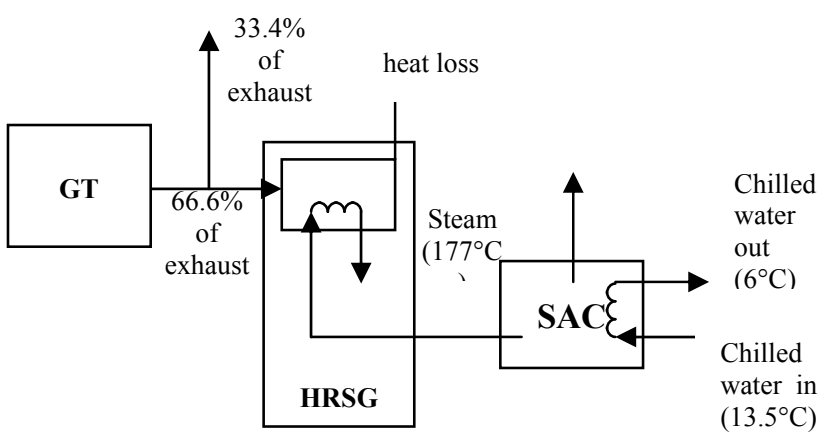

Fig. 6. Schematic diagram for UTP District Cooling Plant.

\section{RESULTS AND DisCUSSIONS}

For the evaluation of $\mathrm{CO}_{2}$ emissions, the chilled water data of UTP Gas district cooling plant were used. Based on historical data for September 2011,the amount of heat loss for GT, HRSG and SAC was estimated using Eq.(3), (4) and (7) as indicated in Fig. 7. In the case $100 \%$ of exhaust heat released to the environment from GT, it shows that GT contributed the mostheat loss with an average 10, $875 \mathrm{kWh}$ while 5, $681 \mathrm{kWh}$ and 1, $757 \mathrm{kWh}$ for HRSG and SAC respectively. This implies that the total amount of exhaust heat released to the environment without heat recovery is approximately $18,000 \mathrm{kWh}$ daily.

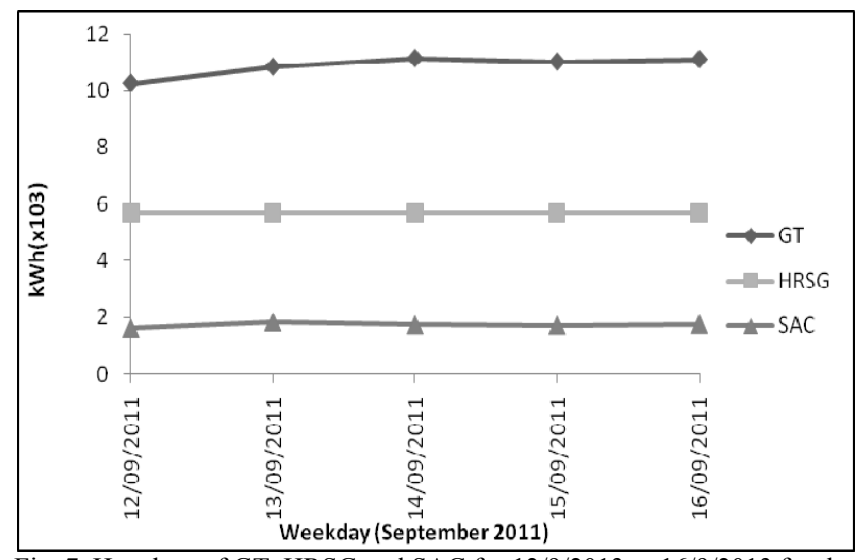

Fig. 7. Heat loss of GT, HRSG and SAC for 12/9/2013 to 16/9/2013 for the case of $100 \%$ of exhaust heat released to the environment.

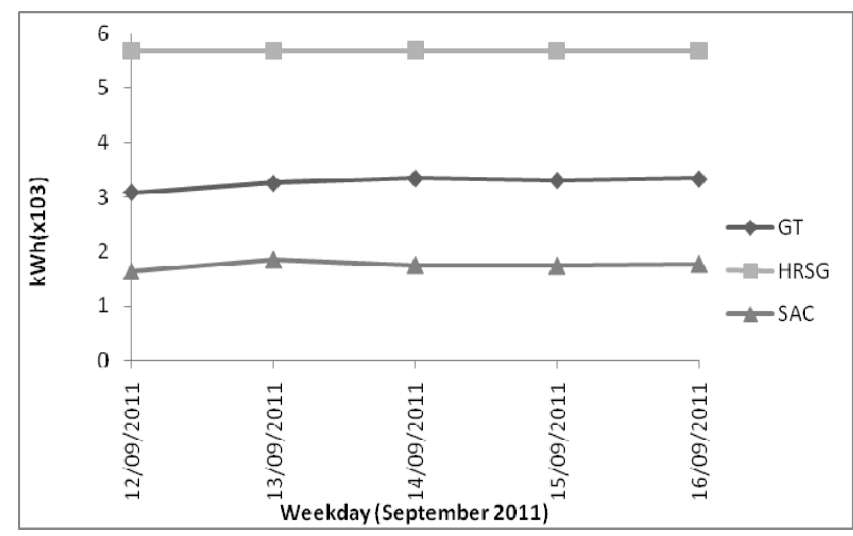

Fig. 8. Heat loss of GT, HRSG and SAC for $12 / 9 / 2013$ to $16 / 9 / 2013$ for the case of $33.4 \%$ of exhaust heat released to the environment.

$\mathrm{CO}_{2}$ emissions can be reduced from power generation by implementing the best practice of technology. Fig. 8 shown, by utilization of exhaust heat from the GT to generate chilled water by absorption process will reduce the amount of exhaust heat released to the environment.

Fig. 8 shows the amount of heat loss from GT, HRSG and SAC by accounting $66.6 \%$ of the exhaust heat used for steam generation in the HRSG. The results indicate the average amount of the estimated heat loss from the GTduring this period is equivalent to $3,262 \mathrm{kWh}$ daily. From the analysis, it is estimated that the total average heat loss from GT, HRSG and SAC due to absorption process during this period is 10 $700 \mathrm{kWh}$. It is shown by applying the absorption technology for a chilled water generation will reduce the amount of heat loss and it is also reduced the amount of $\mathrm{CO}_{2}$ being released to the environment.

The estimation of $\mathrm{CO}_{2}$ is used conversion factor from [13]. Fig. 9 shows the results for the estimated amount of $\mathrm{CO}_{2}$ emitted to the environment by the GT and HRSG respectivelyduring chilled water production using exhaust heat from GT. 


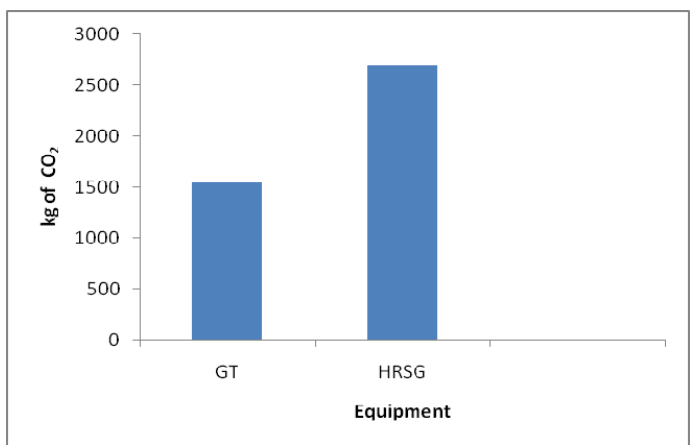

Fig. 9. The estimated amount of $\mathrm{CO}_{2}$ by GT and HRSG for the case of $33.4 \%$ of exhaust heat released to the environment.

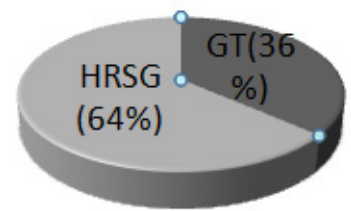

Fig. 10. The estimated amount of $\mathrm{CO}_{2}$ emission released to the environment by percentage.

Fig. 9 shows the estimated amount of $\mathrm{CO}_{2}$ released to the environment by GT and HRSG are $1500 \mathrm{~kg}$ and $3000 \mathrm{~kg}$ respectively. Fig. 10 indicates that $\mathrm{HRSG}$ as the main contributor for $\mathrm{CO}_{2}$ emission to the environmentamounting to $64 \%$ from the total. While GT is about $36 \%$ of $\mathrm{CO}_{2}$ being released to the environment.However, if $100 \%$ of the exhaust heat are released to the environment, the amount of $\mathrm{CO}_{2}$ is approximately $9000 \mathrm{~kg}$ as shown in Fig. 11.

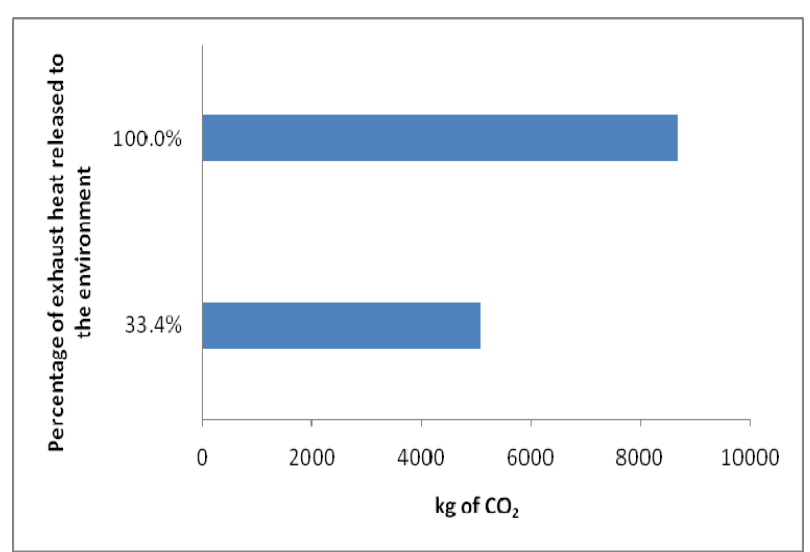

Fig. 11. The estimated amount of $\mathrm{CO}_{2}$ by GT, HRSG and SAC for the case of $33.4 \%$ and $100 \%$ of exhaust heat from GT released to the environment.

From the analysis, it is proven that the chilled water production from exhaust heatresulted in reduction of $\mathrm{CO}_{2}$ emission to the environment. This supports the findings from S.I. Gilani et al. [14] which reported that saving of 5050 tons of $\mathrm{CO}_{2}$ emission for UTP throughout the year 2007.

\section{CONCLUSION}

The production of chilled water using exhaust heat of the district cooling plant enhanced the productivity of the plant. In addition, it also assists in reducing the amount of $\mathrm{CO}_{2}$ emission to the environment.The estimated amount of $\mathrm{CO}_{2}$ emission calculated for $100 \%$ of the exhaust heat emission to the environment is $9000 \mathrm{~kg}$ while $5000 \mathrm{~kg}$ when it is recovered for chilled water production. Thus, the heat recovery process mitigates $44 \%$ of $\mathrm{CO}_{2}$ being released to the environment.

\section{ACKNOWLEDGMENT}

The authors would like to express their appreciation to the support by Ministry of Higher Education Malaysia, MOSTI and Universiti Teknologi Petronas (UTP) for the project.

\section{REFERENCES}

[1] B. Aklilu and S. Gilani, "Mathematical modeling and simulation of a cogeneration plant," Applied Thermal Engineering, vol. 30, pp. 2545-2554, 2010.

[2] W. Graus and E. Worrell, "Methods for calculating $\mathrm{CO}_{2}$ intensity of power generation and consumption: A global perspective," Energy Policy, vol. 39, pp. 613-627, 2011.

[3] U. Çakir, K. Çomakli, and F. Yüksel, "The role of cogeneration systems in sustainability of energy," Energy Conversion and Management, vol. 63, pp. 196-202, 2012.

[4] H. Ong, T. Mahlia, and H. Masjuki, "A review on energy scenario and sustainable energy in Malaysia," Renewable and Sustainable Energy Reviews, vol. 15, pp. 639-647, 2011.

[5] G. Chicco and P. Mancarella, "Assessment of the greenhouse gas emissions from cogeneration and trigeneration systems. Part I: Models and indicators," Energy, vol. 33, pp. 410-417, 2008

[6] H. H. Masjuki, T. M. I. Mahlia, I. A. Choudhury, and R. Saidur, "Potential $\mathrm{CO}_{2}$ reduction by fuel substitution to generate electricity in Malaysia," Energy Conversion and Management, vol. 43, pp. 763-770, April, 2002.

[7] S. Nazari, O. Shahhoseini, A. Sohrabi-Kashani, S. Davari, R. Paydar, and Z. Delavar-Moghadam, "Experimental determination and analysis of $\mathrm{CO}_{2}, \mathrm{SO}_{2}$ and NOx emission factors in Iran's thermal power plants," Energy, vol. 35, pp. 2992-2998, 2010.

[8] C. Hendriks, E. de Visser, D. Jansen, M. Carbo, G. J. Ruijg, and J. Davison, "Capture of $\mathrm{CO}_{2}$ from medium-scale emission sources," Energy Procedia, vol. 1, pp. 1497-1504, 2009.

[9] A. Majid, M. Amin, S. A Sulaiman, I. Ibrahim, and Z. Baharddin, "Causal Model for Peak and Off Peak Waste Heat Recovery for Chilled Water Production," 2012.

[10] G. F. M. de Souza, Thermal Power Plant Performance Analysis: Springer, 2012.

[11] Z. A. A. Karim and P. W. Yongo, "Analytical Models for Energy Eudit of Cogeneration Plant," Journal of Applied Sciences, vol. 11, pp. 1519-1527, 2011.

[12] N. B. Adzuieen Nordin, M. Amin A. Majid, and S. Amear S. Ariffin, "Evaluation of Carbon Dioxide Emission Using Energy Analysis Approach: A Case Study of a District Cooling Plant," International Journal of Computer and Electrical Engineering, vol. vol. 5, pp. 284-287, 2013.

[13] R. Kannan, K. Leong, R. Osman, H. Ho, and C. Tso, "Gas fired combined cycle plant in Singapore: energy use, GWP and cost-a life cycle approach," Energy Conversion and Management, vol. 46, pp. 2145-2157, 2005.

[14] S. Gilani, M. Amin, and C. Rangkuti, "Reduced $\mathrm{CO}_{2}$ Emission by Cogeneration Plants: A Case Study of Two Co-generated Gas District Cooling Plants in Malaysia," in Proc. of the International Conference on Cooling and Heating Technologies 2008 (ICCHT2008), 2008.

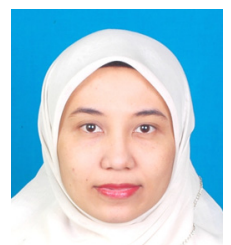

Adzuieen Nordin is a senior lecturer in the Mechanical Engineering Department of Politeknik Ungku Omar, Malaysia since 2003. She graduated with bachelor degree B.Sc. (Hons.) Mechanical Engineering (Manufacturing) 2002 from Universiti Teknologi Malaysia, Malaysia and M. Ed. Technical and Vocational 2003 from Kolej Universiti TeknologiTun Hussein Onn, Malaysia.

Currently she is pursuing Ph.D in Mechanical Engineering. Her research interest is on Carbon dioxide emission and Cogeneration plant. Besides, she is registered as an ASHRAE member since 2011. She is also a Graduate Member (Mechanical Engineering) of the Institution of Engineers, Malaysia (IEM), since 2011.

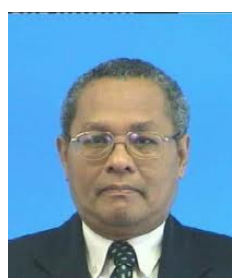

M. Amin A. Majid received Ir. (1976), in Mechanical Engineering from Institut Teknologi Bandung-Indonesia, M. Eng. (1981) from Asian Insitute Technology, Thailand and Ph.D (1994) from University Malaya, Malaysia.

$\mathrm{He}$ is associate professor in Mechanical Engineering Department, Universiti Teknologi Petronas (UTP), Malaysia. His current research interests include energy system, manufacturing optimization and asset management. 